\title{
Penetration of tobramycin sulphate into the human eye
}

\author{
A. PETOUNIS, G. PAPAPANOS, AND C. KARAGEORGIOU-MAKROMIHELAKI \\ From the Department of Experimental Pharmacology, Athens University, and the Eye Clinic, \\ General Hospital of Corinth, Athens
}

SUMMARY Tobramycin sulphate, a new aminoglycoside antibiotic, was injected intramuscularly ( 80 and $100 \mathrm{mg}$ ) and subconjunctivally $(10 \mathrm{mg})$ into patients, and the concentrations of the drug in serum and aqueous humour were determined 1 hour after the injection by an agar wall diffusion plate method. The intramuscular administration of tobramycin produced insignificant and noninhibitory concentrations in the aqueous humour, while therapeutically effective levels of the antibiotic appeared in the aqueous after subconjunctival administration of tobramycin (mean: $18.9 \mu \mathrm{g} / \mathrm{ml}$ ). These data suggest that tobramycin sulphate may be of value in the treatment of ocular infections.

Aminoglycosides are broad spectrum antibiotics widely used in the treatment of ocular infections and for postoperative prophylaxis. Tobramycin sulphate is a new water-soluble, parenterally administered antibiotic of the aminoglycoside group, derived from Streptomyces tenebarius. Its chemical structure, kinetics, pharmacodynamics, and antimicrobial properties closely resemble those of gentamicin (Bodey and Stewart, 1972; Dienstag and New, 1972). It has been proved that tobramycin is more effective than gentamicin against pseudomonas strains in vitro (Traub and Raymont, 1972; Levison and Kaye, 1974; Wretlind and Gezelius, 1976), and it has been reported that it seems to be less toxic than gentamicin (Federspil, 1974). The peak serum concentration of tobramycin occurs between 30 and 90 minutes after intramuscular administration, and detectable levels persist for as long as 6 to 8 hours (Goodman and Gilman, 1975). There is some information on the intraocular penetration of tobramycin in rabbits (Purnell and MacPherson, 1974; Uwayadah and Faris, 1976), but the penetration of the antibiotic into the human eye after administration by various routes has not yet been reported.

The present study was carried out to determine the concentration of tobramycin sulphate in the serum and aqueous humour of patients after intramuscular and subconjunctival administration of the antibiotic.

Address for reprints: Dr Andrew D. Petounis, Department of Experimental Pharmacology, School of Medicine, Athens University, Goudi 609, Athens, Greece

\section{Patients and methods}

Thirty-one patients, aged 58 to 82 years, scheduled for routine cataract extraction under local anaesthesia were selected for this study. All had a normal anterior segment on clinical examination and none of them had a history of drug allergy, renal disease, or any other contraindications to tobramycin administration.

The patients were divided into 3 groups as follows: In the first group each one of 9 patients was given $80 \mathrm{mg}$ of tobramycin in a single intramuscular injection; in the second group each of 7 patients was given $100 \mathrm{mg}$ in a single intramuscular dose; in the third group each of 15 patients was given $10 \mathrm{mg}$ of tobramycin subconjunctivally in the eye to be operated upon. The eye was anaesthetised with benoxinate $0.4 \%$ eye drops, and $0.25 \mathrm{ml}$ $(10 \mathrm{mg})$ of the tobramycin solution was injected subconjunctivally in the inferior half of the globe by means of a tuberculin syringe with a $27 \mathrm{G}$ needle. The patients in all 3 groups received the antibiotic 1 hour before operation. The eyes were prepared for routine cataract extraction. On the operating table, after retrobulbar anaesthesia, lid block, and conjuctival flap dissection, a keratome making a $3 \mathrm{~mm}$ incision was inserted in the anterior chamber at 12 o'clock. Simultaneously a tuberculin syringe with a $25 \mathrm{G}$ needle was introduced into the chamber below the keratome and $\mathbf{0 . 2} \mathrm{ml}$ of aqueous humour was aspirated. At the same time a venous sample (4 to $5 \mathrm{ml}$ ) was also collected. The operation was continued in routine fashion. The blood and 
Table 1 Human serum and aqueous humour tobramycin levels in $\mu \mathrm{g} / \mathrm{ml} 60$ minutes after a single intramuscular injection (80 $\mathrm{mg}$ in group I and $100 \mathrm{mg}$ in group II) and $a$ single subconjunctival injection of $10 \mathrm{mg}$ of tobramycin (group III)

\begin{tabular}{|c|c|c|c|c|c|c|}
\hline \multirow{2}{*}{ Subjects } & \multicolumn{2}{|l|}{ Group I } & \multicolumn{2}{|c|}{ Group II } & \multicolumn{2}{|c|}{ Group III } \\
\hline & Serum & Aqueous & Serum & Aqueous & Serum & Aqueous \\
\hline 1 & $2 \cdot 0$ & 0.7 & $3 \cdot 1$ & 0.4 & $1 \cdot 15$ & 17 \\
\hline 2 & $2 \cdot 8$ & 0.2 & $5 \cdot 2$ & $1 \cdot 6$ & $1 \cdot 10$ & 20 \\
\hline 3 & $5 \cdot 0$ & $0 \cdot 2$ & $4 \cdot 2$ & $1 \cdot 3$ & $1 \cdot 15$ & 15 \\
\hline 4 & $1 \cdot 5$ & $0 \cdot 3$ & $11 \cdot 0$ & 1.9 & 0.57 & 16 \\
\hline 5 & $2 \cdot 8$ & 0.8 & $6 \cdot 0$ & 0.2 & 0.40 & 20 \\
\hline 6 & $9 \cdot 0$ & 0.2 & $11 \cdot 0$ & $2 \cdot 6$ & 0.36 & 18 \\
\hline 7 & $5 \cdot 0$ & $0 \cdot 3$ & $8 \cdot 4$ & $1 \cdot 4$ & $0 \cdot 38$ & 22 \\
\hline 8 & $5 \cdot 2$ & $0 \cdot 2$ & & & $0 \cdot 78$ & 17 \\
\hline 9 & $3 \cdot 3$ & $0 \cdot 2$ & & & $1 \cdot 40$ & 19 \\
\hline 10 & & & & & 0.80 & 23 \\
\hline 11 & & & & & $0 \cdot 50$ & 12 \\
\hline 12 & & & & & $1 \cdot 12$ & 21 \\
\hline 13 & & & & & 0.90 & 20 \\
\hline 14 & & & & & 0.42 & 24 \\
\hline 15 & & & & & 0.20 & 20 \\
\hline Mean & $\begin{array}{r}4 \cdot 07 \pm \\
2 \cdot 28\end{array}$ & $\begin{array}{r}0.30 \pm \\
0.26\end{array}$ & $\begin{array}{r}6.9 \pm \\
3 \cdot 21\end{array}$ & $\begin{array}{c}1.34 \pm \\
0.8\end{array}$ & $\begin{array}{r}0.74 \pm \\
0.37\end{array}$ & $\begin{array}{r}18.9 \pm \\
3.17\end{array}$ \\
\hline
\end{tabular}

aqueous samples, packed in ice, were delivered within 1 hour to the laboratory for antibiotic assay.

\section{ASSAY METHOD}

The antibiotic concentration in serum and aqueous humour was determined by an agar wall diffusion plate method (Bennett et al., 1966). Petri dishes contained a base agar layer (pH 6.8), overlaid with a seeded layer prepared with a suspension of Bacillus subtilis NCTC 8236 as test organism. Small holes $(4.5 \times 2.5 \mathrm{~mm})$ were opened and filled with samples. All samples were run in duplicate. Using standard concentrations of six different tobramycin solutions a standard curve was plotted on semilog paper. The diameter zones were measured in millimetres by a microestimator after 24 hours of incubation at $37^{\circ} \mathrm{C}$. Concentrations of the antibiotic were determined in $\mu \mathrm{g} / \mathrm{ml}$ by reading the concentration directly from the standard curve derived stimultaneously from the similarly prepared known concentration of antibiotic diluted in human serum and saline.

\section{Results}

The concentrations of tobramycin sulphate found in the aqueous humour and serum 1 hour after intramuscular and subconjunctival antibiotic ad- ministration are listed in Table 1 and are shown in Fig. 1 schematically.

Group I. A single intramuscular injection of $80 \mathrm{mg}$ of tobramycin resulted in a mean serum level of $4.072 \pm 2.28 \mu \mathrm{g} / \mathrm{ml}$ and a mean aqueous concentration of $0.3 \pm 0.26 \mu \mathrm{g} / \mathrm{ml}$.

Group II. $100 \mathrm{mg}$ of tobramycin injected intramuscularly produced a mean serum concentration of $6.94 \pm 3.2 \mu \mathrm{g} / \mathrm{ml}$ and an average aqueous humour level of $1.33 \pm 0.8 \mu \mathrm{g} / \mathrm{ml}$.

Group III. Sixty minutes after a single subconjunctival dose of $10 \mathrm{mg}(0.25 \mathrm{ml})$ of tobramycin sulphate the mean antibiotic serum level was $0.74 \pm 0.37 \mu \mathrm{g} / \mathrm{ml}$ and the average tobramycin aqueous concentration was $18.9 \pm 3 \cdot 17 \mu \mathrm{g} / \mathrm{ml}$.

All the patients had a normal postoperative course and none showed any anterior segment changes resulting from the subconjunctival injection of tobramycin.

\section{Discussion}

The treatment of ocular infections caused by Gramnegative bacteria, and especially by Pseudomonas aeruginosa strains, cannot be regarded as satis-

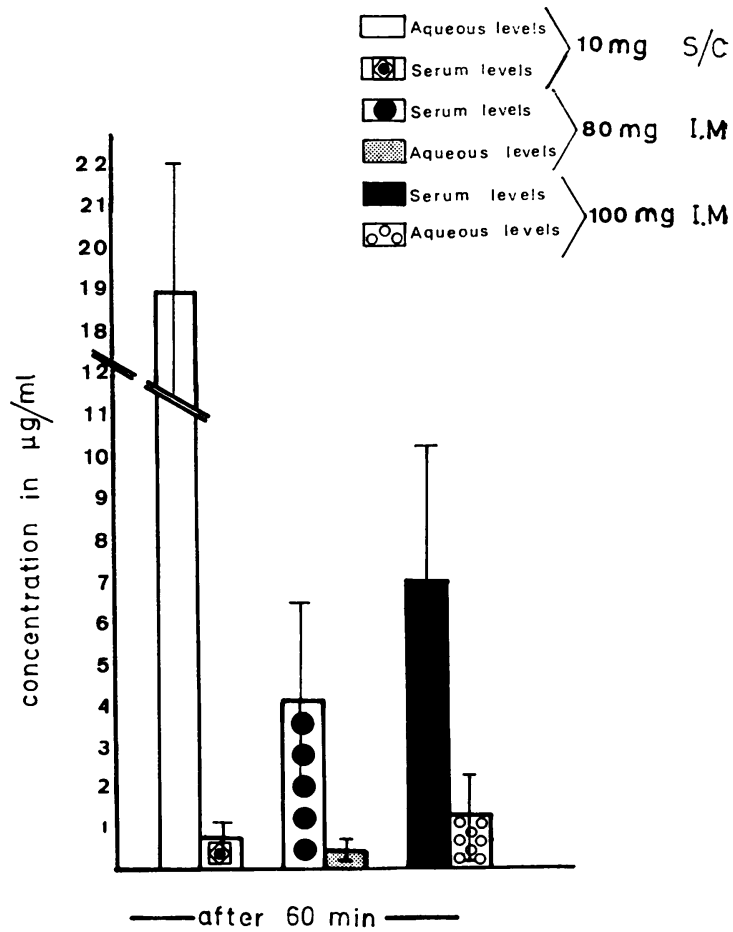

Fig. 1 Mean serum and aqueous humour tobramycin levels following intramuscular and subconjunctival injection in man 
factory. Tobramycin sulphate is a new antibiotic of the aminoglycoside group that seems to be more effective, at least in vitro, against these bacteria, as reported previously. Our results show that tobramycin penetrates the eye poorly after intramuscular injection, while therapeutically effective concentrations in the aqueous humour resulted from subconjunctival administration.

The intramuscular injection of tobramycin in a single dose of $80 \mathrm{mg}$ produced aqueous levels of the antibiotic $(0 \cdot 3 \pm 0 \cdot 26 \mu \mathrm{g} / \mathrm{ml})$ which are much lower than the minimum inhibitory concentration for the majority of the pathogenic bacteria (Jaffe et al., 1974). When $100 \mathrm{mg}$ of tobramycin was injected intramuscularly, the antibiotic level produced in the aqueous fluid $(1.33 \pm 0.8 \mu \mathrm{g} / \mathrm{ml})$ was 4 times higher than that produced by the intramuscular injection of $80 \mathrm{mg}$. This antibiotic level in the aqueous can be effective against some bacteria, but undesirable side effects may be produced by a dose of $100 \mathrm{mg}$ of tobramycin. The inability of tobramycin to penetrate the normal human eye in therapeutic levels was expected and is consistent with published data on other aminoglycosides to which tobramycin is related (Litwak et al., 1969; Furgiuele, 1970; Maclwain et al., 1974). When $10 \mathrm{mg}$ of tobramycin was injected subconjunctivally, the antibiotic level produced 1 hour after administration was much higher than the minimum inhibitory concentration of all the pathogenic bacteria, even Pseudomonas species (Jaffe et al., 1974). The levels of antibiotic obtained in the aqueous after subconjunctival injection are higher than those of other antibiotics of the same group (Furgiuele, 1970; Maclwain et al., 1974). The variations in the mean values of tobramycin aqueous levels observed in our experiments are consistent with other data on tobramycin and other aminoglycosides (Litwak et al., 1969; Uwaydah and Faris, 1976).

Finally, we can conclude that tobramycin levels in the aqueous humour obtained from subconjuctival administration were sufficient to inhibit all strains of pathogenic bacteria, while an efficient barrier prevents the diffusion of tobramycin from serum to the primary aqueous humour of the normal human eye. The intramuscular administration of the antibiotic produces subtherapeutic levels in the aqueous humour.

\section{References}

Bennett, J., Brodie, J., Benner, E., and Kirby, W. (1966). Simplified, accurate method for antibiotic assay of clinical specimens. Applied Microbiology, 14, 170-178.

Bodey, C., and Stewart, D. (1972). In vitro studies of tobramycin. Antimicrobial Agents and Chemotherapy, 2, $109-113$.

Dienstag, J., and New, H. (1972). In vitro studies of tobramycin, an aminoglycoside antibiotic. Antimicrobial Agents and Chemotherapy, 1, 41-45.

Federspil, P. (1974). Experimental and clinical studies on the ototoxitity of tobramycin. In: Tobramycin, Selected Proceedings from the Eighth International Congress of Chemotherapy, Athens, September 1973, pp. 38-43. Excerpta Medica: Amsterdam.

Furgiuele, F. P. (1970). Penetration of gentamycin into the aqueous humor of human eyes. American Journal of Ophthalmology, 69, 481-483.

Goodman, L., and Gilman, A. (1975). In The Pharmacological Basis of Therapeutics, 5th edn., pp. 1175-1176. Macmillan: New York.

Jaffe, G., Ravreby, W., Meyers, B., and Hirschman, S. (1974). Clinical study of the use of the aminoglycoside tobramycin for therapy of infections due to Gram negative bacteria. Antimicrobial Agents and Chemotherapy, 5, 75-81.

Levison, M. E., and Kaye, D. (1974). In vitro comparison of four aminoglycoside antibiotics: sisomicin, gentamycin, tobramycin and BBK8. Antimicrobial Agents and Chemotherapy, 5, 667-669.

Litwak, K. Petit, T., and Johnson, B. (1969). Penetration of gentamycin administrated intramuscularly and subconjunctivally into aqueous humor. Archives of Ophthalmology, 82, 687-693.

Macllwaine, W., Sande, M., and Mandel, G. (1974). Penetration of antistaphylococal antibiotics into the human eye. American Journal of Ophthalmology, 77, 589-592.

Purnell, W., and McPherson, S. (1974). The effect of tobramycin on rabbit eyes. American Journal of Ophthalmology, 77, 578-582.

Traub, W., and Raymond, E. (1972). Evaluation of the in vitro activity of tobramycin as compared with that of gentamicin sulfate. Applied Microbiology, 23, 4-7.

Uwaydah, M., and Faris, B. (1976). Penetration of tobramycin sulfate in the aqueous humor of the rabbit. Archives of Ophthalmology, 94, 1173-1174.

Wretlind, B., and Gezelius, L. (1976). Sensitivity of isolated Pseudomonas aeruginosa to amikacin, gentamicin, sisomicin and tobramycin. IRCS, Journal of Medical Science. 4, 156. 